\title{
Éticas para la esperanza de una educación inclusiva ${ }^{1}$
}

\author{
Ethics for the hope of an inclusive education
}

\author{
Ester Caparrós Martín \\ e-mail: ester.caparros@,uma.es \\ Universidad de Málaga. España
}

Mayka García García

e-mail: mayka.garcia@uca.es Universidad de Cádiz. España

\section{Resumen}

El texto que presentamos trata de hacer confluir los planteamientos que el autor Paulo Freire tiene sobre la ética y la educación liberadora con el modo desde el que pensamos la educación inclusiva. Para ello, partimos de una postura pedagógica, ya que pretendemos poner de relieve y nombrar cuáles son los valores y los principios de la política y la práctica inclusiva, a fin de profundizar en su naturaleza y en su sentido. Es por ello por lo que hablamos desde la ética y no desde la norma, ni el derecho; entendemos que la ética, como bien sostiene Freire (2008, p. 17), es «inseparable de la práctica educativa» porque alude a la responsabilidad que tenemos para crear en convivencia un mundo más justo y democrático. Abordamos, pues, aquellas cuestiones que dicha ética freireana permite para reflexionar y analizamos qué valores, de los que emergen en los procesos inclusivos, se promueven desde una lógica de respeto por las diferencias. Se propone además una serie de éticas que reflejan cada una de las cualidades pedagógicas que consideramos que ha de tener la educación inclusiva. Para finalizar, se plantean una serie de focos de reflexión que posibiliten seguir pensando cómo equilibrar el respeto por lo singular y lo común. En definitiva, se trata de una apuesta esperanzadora que pretende reflejar la esencia de la ética como un modo de cultivar una educación respetuosa, democrática y equitativa que respete las diferencias desde su inherencia humana.

Palabras clave: ética; pedagogía de la esperanza; educación inclusiva; valores; igualdad; subjetividad.

\section{Abstract}

This paper brings together Paulo Freire's ethical approaches and his pedagogy of liberation. Both dimensions relate to the way we conceive an inclusive education. As we intend to highlight the values and principles of educational practice and inclusive education, our starting point is Freire's pedagogical position. From there, we deepen into its nature and significance. That is why the paper speaks from an ethical standpoint and not from a normative or legal one. As Freire (2008, p. 17) argues, ethics is «attached to the educational practice», so it alludes to the responsibility we hold as human beings in creating an equitable and democratic world. We show the questions of the Freirean etbics that allow us to reflect and to analyze which values are promoted in the inclusive processes. Moreover, we ponder about the logic of respect for differences in the inclusive processes. As a result, we propose specific ethical procedures that reflect all the pedagogical qualities required in inclusive education environments. Several points of reflection are shown to continue the dialogue about how to balance our respect for the singular and the common. It is a hopeful gamble that aims to reflect the essence of ethics as a way of cultivating a respectful, democratic, and equitable education that respects differences from their inherent humanness.

Keywords: ethic; pedagogy of hope; inclusive education; values; equality; subjetivity.

Recibido / Received: 15-01-2021

Aceptado / Accepted: 02-06-2021

Publicación en linea / Published online: 28-07-2021

Cómo referenciar este artículo / How to reference this article:

Caparrós Martín, E., \& García García, M. (2021). Éticas para la esperanza de una educación inclusiva. Tendencias Pedagógicas, 38, pp. 83-97. doi: 10.15366.tp2021.38.008.

\footnotetext{
${ }^{1}$ Las reflexiones que abordamos en este texto son fruto del trabajo que realizamos dentro de la Red Docente de Excelencia sobre Inclusión e Innovación (REDIN). Esta RED está formada por profesorado de reconocido prestigio de diversas universidades a nivel nacional (Málaga y Cádiz) e internacional (RomaTre y La Sapienza di Roma); perteneciente a la convocatoria de Ayudas de la acción sectorial 42 y financiada por el Plan Propio Integral de Docencia de la Universidad de Málaga para el curso académico 2019/2020 y está coordinada por la profesora Ester Caparrós Martín.
} 


\section{Introducción}

Es por esa ética inseparable de la práctica educativa, no importa si trabajamos con niños, jóvenes o adultos, por la que debemos luchar. Y la mejor manera de luchar por ella es vivirla en nuestra práctica, testimoniarla con energía a los educandos, en nuestras relaciones con ellos. (Freire, 1997, p. 18)

Vivir la ética en la práctica educativa es una forma de concebir y de situarse en el mundo con implicación y responsabilidad para con las otras y los otros. Un compromiso que nace desde sí, pero que es siempre en relación; pues, como sostiene Freire (1970): «Nadie libera a nadie, ni nadie se libera solo. Los hombres se liberan en comunión» (p. 36). Pero ¿Por qué nos referimos a la ética en la educación y qué relación guarda, concretamente, con la educación inclusiva?

Para nosotras, apostar por la educación inclusiva hoy es una oportunidad que nos abre a pensar renovadamente la escuela. Esto es, ni más ni menos, que una invitación a planificarla, organizarla, imaginarla y re-crearla desde otras perspectivas que han de tener como pilar fundamental el respeto por lo singular — derivado de las propias subjetividades_- a la vez que por lo común — proveniente de las relaciones que establecemos en comunidad- (Caparrós, Bordini y Rodríguez, 2020).

En este sentido, son numerosas las autoras y los autores que, desde esta mirada inclusiva, hacen una llamada a la ética freireana como posicionamiento pedagógico; precisamente para situarla como punto de partida de esta forma de entender la educación y, por ende, la vida (Booth, 2002 y 2006; Corbett, 1996; Escudero, 2006; Escudero y Martínez, 2011; Greenstein, 2015; Parrilla, 2002; Slee, 1995).

Esta mirada ética hacia lo educativo es una llamada a ir más allá de la moral, porque, aunque es evidente que en toda educación hay moral (también en todo adoctrinamiento), como bien sugieren Bárcena y Melich (2014):

Lo que es propio de la educación no es la moral sino la ética. A diferencia de la moral, la ética es un acontecimiento, es la respuesta a la demanda del otro en una situación inaudita e imprevisible. Por eso no hay normas éticas, ni principios éticos, ni códigos éticos. Todo ello forma parte de la moral. (p. 13)

Como sostienen los autores, la ética se sitúa fuera de la norma, de lo impuesto, de los deberes y obligaciones, que son más propias de lo moral. Por ello, la apuesta por la ética en educación se encuentra en consonancia con nuestro posicionamiento sobre educación inclusiva, ya que hablar de inclusión educativa no es solo hablar de derechos o metodologías didácticas; sino que descansa en esa perspectiva pedagógica y política de la ética que supone «una fisura, una quiebra, una herida de lo legislado, de los marcos públicos (legales, jurídicos y morales) instituidos» (Opus cit. pp. 13-14).

Esto precisa un posicionamiento firme sobre los valores, los principios y la acción política y práctica que fundamentan dicha ética, que ayude a definir qué y cómo atender lo individual y lo colectivo —equilibrando ambos_-; de manera que, como sostiene Freire (1990), podamos conformar así la cultura - sin que esta se constituya sobre la base de restricciones morales.

En las siguientes líneas tratamos de hacer confluir precisamente esto, ética y educación inclusiva; es decir, los planteamientos que sobre la ética y la educación liberadora ha ido realizando el autor Paulo Freire, con nuestra posición pedagógica en torno a la noción de inclusión. Con ello, queremos abrimos a la esperanza de repensar la lógica desde la que se mueve la educación hoy, tanto desde sus prácticas y sus valores, como desde sus políticas, y poder reflexionarlos. Se trata de una apuesta esperanzadora que plantea qué éticas son necesarias y desde qué sentido se proponen para la consecución de una educación respetuosa, democrática y equitativa que respete las diferencias desde su inherencia humana. Tener en cuenta que las diferencias forman parte de la subjetividad significa que, en educación, tan importante es la transmisión cultural como las relaciones que establecemos para que los modos en los que nombramos y transferimos la cultura no adoctrinen, no anulen o nieguen las singularidades.

Hacemos, por tanto, una apuesta por abordar las diferencias desde la noción de equidad (Contreras, 2002; Larrosa y Skliar, 2001) y por cuidar cómo desde las distintas éticas hay un planteamiento inclusivo de apuesta por dicha singularidad, que es construida en comunidad. En este sentido, nombraremos al final, cómo aprender a mirar el yo que mira, que es, entre otras cuestiones, aprender a mirar 
hacia dentro, requiere de una disposición que va más allá de planteamientos solipsistas. Pues mirar hacia sí requiere reconocer(nos) también en las relaciones que establecemos con las otras y los otros (Caparros, 2015; Sierra y Caparrós, 2017).

\section{Lo que posibilita la ética freireana a la educación inclusiva}

Consideramos que la ética, como ya nos advertía Freire (2008), es «inseparable de la práctica educativa» (p. 17). Para el autor brasileño, la ética educativa es entendida como práctica de libertad, «una praxis social para la liberación de los seres humanos» (Freire, 1974). Este posicionamiento que une la educación a la perspectiva ética liberalizadora está sostenido por una reflexión continua en torno a la pregunta: cómo educar a los seres humanos para que sean libres, para que no sean sometidos ni manipulados y no sean infravalorados por sus cualidades propias y sus diferencias.

En este sentido, Allan (2005) nos recuerda cómo la educación inclusiva es un proyecto ético que nos responsabiliza a todas las personas por igual. De modo que, si la educación, entendida como práctica ética de la libertad, nos habla de la responsabilidad para con las otras y los otros, no podemos olvidar que el adjetivo «inclusivo» no hace más que señalar dicho compromiso para con todas y todos como sujetos singulares que con-vivimos conjuntamente. A esta lectura sobre la educación inclusiva, Corbett y Slee (2000) añaden la importancia de convertirnos en lo que ellos denominan «vigilantes culturales». Una tarea que requiere estar siempre atentas para: (i) examinar las inercias tanto sociales como las propias; (ii) detenernos a pensar de qué modo abordamos las dificultades y los obstáculos que se presentan; y (iii) reflexionar sobre cómo gestionamos el esfuerzo y desde dónde (en relación a qué principios y qué valores). Todo ello como una manera de evitar que lo que vaya surgiendo, fruto de movimientos críticos, se torne un statu quo.

Por otro lado, Slee (2012) nos recuerda que la educación inclusiva — concebida como educación crítica- se torna «cívica» allá donde ética y política se reconcilian y se necesitan bajo un proyecto común. Esto refleja cómo la ética proporciona una base a la política — que es eminentemente concebida como saber directivo que orienta la mirada hacia el bien del ser humano y de la ciudadanía—, y la dirige hacia la vida «buena» y justa. De este modo, la ética es completada por la política en la propia acción, posibilitando un mayor nivel de concreción (Jover \& Gil Cantero, 2003).

\section{La Educación Inclusiva como «lugar ético» desde donde se vive}

La noción de ética ha sido definida y entendida de distintos modos y en diferentes épocas y culturas. Nos gustaría rescatar aquí la raíz etimológica que proviene de la palabra griega ethos para aludir al significado que la define como «lugar desde dónde se vive». Este significado pone de manifiesto cómo la ética guarda una estrecha relación con el sentido que para nosotras tiene la noción de educación inclusiva; esta es una forma de ser, de estar en el mundo social y educativo y que nos implica.

En esencia, la ética, al igual que la ciencia, se ocupa de qué es lo moral —como acuerdo social que construye la norma—; de cómo se justifica — desde qué paradigma—; y de cómo se aplica —qué cuestiones morales y dilemas concretos- Pero no se circunscribe a ello, pues entonces hablaríamos de la teorización de la moral. La ética pone en relación la formación moral, la experiencia y la reflexión personal, de ahí que suponga un acontecimiento, en palabras de Bárcena y Melich (2014); y ese acontecimiento implica una práctica de libertad que se ha de asumir en el escenario de una relación de respeto (Freire, 1992).

Existen distintas formas de entender y cultivar la ética dependiendo de su objeto de estudio y de los distintos atributos categóricos que se le ofrezcan. Así, las categorías duales «ética heterónoma»«ética autónoma» colocan a la ética en diferentes perspectivas de comprensión. En el primer caso, la ética heterónoma se presenta como discurso normativo asimilacionista, ya que las normas o el sistema moral del que se parte para analizar, comprender y habitar el mundo es, de algún modo, impuesto desde la comunidad; o bien son los sujetos individuales quienes sienten la necesidad de asumir dichas normas — porque es lo habitualmente aceptado por todas y todos-. Sin embargo, la ética autónoma parte de considerar que las personas somos capaces de elaborar nuestro propio pensamiento, lo que implicaría una toma de postura consciente ante las decisiones de la vida en comunidad.

Lo que nos hacen pensar ambas posturas que colocan al desarrollo de la ética en una situación contrapuesta la una de la otra — en cuanto a visión epistemológica de la realidad — es cómo desde nuestra concepción de educación inclusiva observamos que existen grandes diferencias a la hora de 
apoyarse solo en una u otra perspectiva. A nuestro modo de ver, la concepción inclusiva entiende que la ética heterónoma, al desarrollarla aislada de la ética autónoma, cierra toda posibilidad de creación y elaboración propia por parte de los sujetos ante las cuestiones que le atañen; pues la imposición de ciertas medidas, pautas y normas, aceptadas sin dilación, impide per se salirse de los marcos que cercan los modos de pensar las cuestiones importantes de la vida. Al establecerse como norma, por hábito y costumbre, se niega toda posibilidad de cambio, pues estos no son ni solicitados ni considerados necesarios en un sistema que es controlado y que es moral y comúnmente aceptado.

Sin embargo, puesto que consideramos que la educación inclusiva nos abre a la renovación del pensamiento, tal y como afirmábamos al comienzo, a desarrollar una ética autónoma (que se combine con las normas sociales y culturales que implican el desarrollo de una ética heterónoma) permite a cada quien tomar una posición consciente y clara sobre lo que se hace y cómo se hace; dentro de ese equilibrio entre heteronomía y autonomía que ofrece la ética, esta última posibilita a los sujetos un lugar propio desde el que situarse en la vida e invita a aceptar que existen diversas formas de ser y estar en el mundo al abrir escenarios diversos que ayudan a conformación propia de pensamiento. En este caso, vincular la educación inclusiva al desarrollo de una ética autónoma no conlleva la negación de una ética universal, sino que esta ética universal se configura como marco de la naturaleza humana a partir de la cual se construye la convivencia (Freire, 1999).

\subsection{La capacidad de reconocerse en el otro diferente}

Para continuar con este ejercicio de confluencia entre la ética y la educación inclusiva, asumimos como necesarios los planteamientos que realiza Humberto Maturana (1994) acerca de cómo la ética requiere que pensemos la naturaleza de las relaciones con las otras y los otros desde sí, afirmando que una adecuada ética se constituye en «la preocupación por las consecuencias que tienen las acciones de uno sobre otro, y adquiere su forma desde la legitimidad del otro como un ser con el cual uno configura un mundo social» (p. 257). Como vemos, la preocupación de este autor se sitúa de nuevo en cómo hacer para equilibrar los intereses subjetivos con los intereses colectivos, a fin de crear cultura dentro de una sociedad justa y responsable; tal y como sostienen los planteamientos de la educación inclusiva.

López Melero (2004), siguiendo a Maturana, reconoce esto mismo afirmando que la ética se asienta en el reconocimiento del otro y siempre en la legítima convivencia. Esto significa que la ética es en sí la postura que nos posibilita vivirnos desde y con el otro o la otra. Un proceso que empieza en la propia aceptación (quienes somos y desde dónde nos situamos), y que siempre requiere de la relación con los otros para constituirse (Maturana, 1992). Queremos rescatar la postura de ambos autores para enfatizar la que es nuestra visión sobre la educación inclusiva. De este modo, consideramos que para conformarnos en ese mundo de valores y acciones que supone un proyecto personal necesitamos tener también presente lo colectivo (Camps, 1986). O como sostiene Maturana (1992), si no cultivamos la convivencia, no hay fenómeno social.

\section{Los valores de la Educación Inclusiva}

Para Booth y Ainscow (2016) la educación inclusiva supone un proceso sistemático cuyo propósito radica en llevar una serie de valores a la acción. Ello precisa, como mencionábamos anteriormente, de una ética que sea capaz de identificar la naturaleza de esos valores y principios inclusivos que van surgiendo allá donde la educación inclusiva emerge como proceso. Dado que no hay una única disposición establecida en torno a la acción inclusiva, el que la aceptemos como proceso nos hace correr el riesgo de que aquello que surja pueda ser poco reflexionado o se convierta en norma.

Entendemos que los valores adquieren significados insertos en proyectos de vida y de convivencia, lo que hace que se construyan en un contexto cultural, un espacio y un tiempo que se proyecta. Ello significa que los valores adquieren su esencia en la acción y se constituyen como referentes, tanto de lo que somos como de lo que queremos ser; de dónde estamos y de hacia dónde queremos transitar.

Lo que es común e históricamente vivido - e interpretado- nos ofrece el marco de valores universales que son los que sostienen las conquistas sociales; pero es importante especificar qué conjunto de derechos universales son esencialmente constituidos en la convivencia. Según Maturana (1994), los valores suponen «configuraciones relacionales en la convivencia que obtienen su legitimidad desde 
el amor» (p. 254), entendiendo por amor ese reconocimiento del otro o la otra del que nos habla Scheler (1974).

Teniendo en cuenta lo anterior, nos planteamos ¿qué valores comunitarios pueden encontrarse en el proyecto ético de la educación inclusiva? Para ello, recurrimos al marco que Booth y Ainscow (2016) nos presentan a través de la versión revisada del Index for inclusion que desarrolla un consenso en relación con los mismos, acompañada de los significados actuales que construyen a través de un proceso participativo. Estos autores ya habían presentado, en numerosos trabajos, la esencia ética de la educación inclusiva (Booth, 2006; Booth y Ainscow, 2012) y concretado un conjunto de 11 valores en la primera versión del Index. En este momento dan un paso más allá y desde la orientación subjetiva del desarrollo de los valores presentan un conjunto de 15 en un contexto comunitario. De hecho, esta versión del conocido instrumento supone un estudio en profundidad en relación con los valores, siendo esta la principal aportación de la misma. Utilizan una sugerente metáfora, la del árbol, para representar cómo los valores están en las raíces del mismo, pero también crecen como hojas a medida que se dan las condiciones óptimas para ello; y, de otro lado, existe una preocupación importante por poner palabras al significado de los mismos.

Antes de pasar a profundizar en el marco de valores de referencia, queremos mencionar que existen otros trabajos que reflexionan y sistematizan valores inclusivos, tal y como podemos ver en la Tabla 1. Destacamos el trabajo de Andrés y Sarto (2009), quienes comparan los valores de la ley educativa vigente en el momento de la revisión (LOE) con la primera versión del Index for inclusion (Booth y Ainscow, 2002) y con el trabajo de Castillo (2005), que presenta en 10 valores para el siglo XXI. Esta comparativa es ilustrada en la Tabla 1, en la que nosotras, a fin de actualizarla, hemos incluido una última columna referida a la LOMCE (2013).

Tabla 1.

Comparativa de valores entre los explicitados en normas educativas españolas y los expresados por distintos autores y autoras

\begin{tabular}{llll}
\hline LOE & $\begin{array}{l}\text { Booth \& } \\
\text { Ainscow (2002) }\end{array}$ & $\begin{array}{l}\text { Valores para } \\
\text { el siglo XXI }\end{array}$ & LOMCE \\
\hline Libertad & Libertad & Libertad & Libertad \\
\hline Calidad & Calidad \\
\hline Equidad & Equidad & Equidad \\
\hline Responsabilidad & & Compromiso & Responsabilidad \\
\hline Igualdad & Igualdad & Igualdad \\
\hline Solidaridad & Solidaridad \\
\hline Tolerancia & Tolerancia & Tolerancia \\
\hline Respeto & $\begin{array}{l}\text { Respeto por } \\
\text { la diversidad }\end{array}$ & Diferencia & $\begin{array}{l}\text { Respeto por la } \\
\text { diversidad }\end{array}$ \\
\hline Justicia & Justicia \\
\hline Participación & Participación & \\
\hline Ciudadanía \\
democrática & $\begin{array}{l}\text { Ciudadanía } \\
\text { democrática }\end{array}$ & Civismo & $\begin{array}{l}\text { Ciudadanía } \\
\text { democrática }\end{array}$ \\
\hline \multicolumn{5}{c}{ Honradez } \\
\hline Compasión \\
\hline Derechos \\
\hline Alegría \\
\hline Sostenibilidad & Sostenibilidad \\
\hline Colaboración & Colaboración & Cooperación & Cooperación \\
\hline & Sensibilidad \\
\hline
\end{tabular}

Fuente: elaboración propia a partir de LOE (2006) y LOMCE (2013), Booth y Ainscow (2002), Carrillo (2005) y Andrés y Sarto (2009).

La primera observación que ser deriva de la tabla anterior, si comparamos lo expresado por Booth y Ainscow (2002) y Carrillo (2005), es que apreciamos cómo los valores de la educación inclusiva no se encuentran al margen de otros valores generales socialmente sostenidos y que se asientan en la complejidad posmoderna. En este diálogo emanan los valores de libertad, diversidad/diferencia y ciudadanía 
democrática en la esencia del desarrollo de valores modernistas; un valor que surge como respuesta a la crisis de la que habla la posmodernidad ${ }^{2}$, la sostenibilidad; y otro que nos habla de su orientación comunitaria, la cooperación/colaboración.

Cuando contraponemos las apuestas de naturaleza inclusiva y las contextualizadas en el siglo XXI con las normas educativas, observamos una disfunción entre la orientación de unas y otras respecto de los valores. Las leyes educativas en nuestro contexto responden a una lógica de valores modernista, orientada por la calidad (LOE) y radicalizada de eficiencia en la LOMCE. Ello sitúa el proyecto social, el proyecto educativo y el proyecto personal muy lejos de la propuesta humanista de la ética subjetivista, la cual incorpora emociones y procesos proyectivos susceptibles de ser transformados en claves contextuales, además de situar la utopía como posible.

Booth y Ainscow (2016) explicitan ideas y conceptos como valores de acción, diferenciándolos en tres grandes dimensiones que, según indican, deberían organizar nuestra convivencia:

(i) La dimensión estructural: aglutina aquellos valores que tienen que ver con el desarrollo de las estructuras como marco macro y micro político: equidad, derechos, participación, comunidad y sostenibilidad.

(ii) La dimensión relacional: agrupa a los que definen las relaciones con el otro o la otra: respeto a la diversidad, no violencia, confianza, compasión, honestidad y coraje.

(iii) La dimensión personal: articula lo que los autores consideran que «alimentan el espíritu» y tiene que ver con la esencia de sentimientos y emociones que mueven la educación inclusiva: alegría, amor, esperanza/optimismo y belleza.

Esta categorización nos parece de sumo interés en cuanto que constituye una propuesta más integrada. La diferenciación entre las distintas versiones del Index reside tanto en esta nueva estructuración, que representamos en la siguiente tabla, como en la redefinición y ampliación de valores.

Tabla 2.

Comparativa entre valores de las distintas versiones del Index for Inclusion

\begin{tabular}{|c|c|c|}
\hline $\begin{array}{l}\text { Booth \& Ainscow } \\
(2002)\end{array}$ & Booth \& Ainscow & 16) \\
\hline Libertad & & \multirow{6}{*}{ Estructuras } \\
\hline Equidad & Igualdad & \\
\hline Derechos & Derechos & \\
\hline \multirow[t]{2}{*}{ Participación } & Participación & \\
\hline & Comunidad & \\
\hline Sostenibilidad & Sostenibilidad & \\
\hline $\begin{array}{l}\text { Respeto por la } \\
\text { diversidad }\end{array}$ & $\begin{array}{lll}\begin{array}{l}\text { Respeto } \\
\text { diversidad }\end{array} & \text { a la } \\
\end{array}$ & \multirow[t]{7}{*}{ Relaciones } \\
\hline Tolerancia & No violencia & \\
\hline Honradez & Honradez & \\
\hline \multicolumn{2}{|l|}{$\begin{array}{l}\text { Ciudadanía } \\
\text { democrática }\end{array}$} & \\
\hline Colaboración & Confianza & \\
\hline \multirow[t]{4}{*}{ Compasión } & Compasión & \\
\hline & Coraje & \\
\hline & Amor & \multirow{4}{*}{ Espíritu } \\
\hline & Belleza & \\
\hline \multirow[t]{2}{*}{ Alegría } & Alegría & \\
\hline & $\begin{array}{l}\text { Esperanza/optimis } \\
\text { mo }\end{array}$ & \\
\hline
\end{tabular}

2 Para ahondar en el significado profundo de la modernidad y la posmodernidad en el ámbito de la educación inclusiva se puede consultar: Ocampo-González, A. (2014). Consideraciones epistemológicas para una educación inclusiva. Investigación y posgrado, 29(2), pp. 83-111. 
Fuente: elaboración propia a partir de Booth y Ainscow (2002 y 2016).

Además de lo mencionado, queremos argumentar que hemos elegido el marco de valores de estos autores —desde el año 2016 como referente_- por un lado, porque nos parece que acoge, contextualiza y sistematiza la esencia de la educación democrática; un concepto que se articula bajo el paraguas de las ideas freireanas de justicia, igualdad y participación, aunque actualizado en el presente. Esto permite realizar una lectura de la educación inclusiva entendida como esa práctica política a la que nos remite el autor (Freire,1990,1997). Por otro, porque consideramos que este marco introduce el mundo de las relaciones y las emociones como dimensiones desde las que se construye la educación inclusiva.

El marco de valores definido, desde esta tercera versión revisada del Index, asume la interdependencia de estos como piezas de un puzle que se necesitan y se sostienen; es decir, que no existe una relación jerárquica ni graduada, sino complementaria entre dichos valores, a la vez que de necesidad mutua. Esta idea en relación con la educación inclusiva ya era sustentada por autoras como Stainback y Stainback (1999) quienes apuntaban que «la sociedad (y la escuela) debe ir más allá de la mera celebración de la diversidad, enseñando a los alumnos a comprender las desigualdades sociales y capacitándolos para trabajar activamente en cambiar la sociedad» (p. 39). En este ejemplo se identifican distintos valores inclusivos enlazados, como pueden ser la diversidad, la igualdad y el coraje.

Booth y Ainscow (2016) enfatizan la necesidad de explicitar en cada comunidad los valores tanto en su aspiración como en acción, porque el diálogo en torno a los mismos anima a lo que denominan «alfabetización ética». Hacemos aquí una lectura de dicha alfabetización ética como un proceso comunicativo de naturaleza dialógica (Freire, 1990). En este, a través de la palabra y de la expresión de significados personales subjetivados, creamos y recreamos nuestro pensamiento desde un sentido ético y en un proyecto común, ya que es a través de la racionalidad comunicativa como llegamos a consensos (Habermas, 1987).

Por eso, la educación inclusiva no puede asumir una visión tradicional ni modernista de los valores. En el primer caso, en la visión tradicional, estaríamos ante valores éticos inclusivos impuestos de manera acrítica - aunque supongan un marco común_, lo que implica que estaríamos ante un ejercicio de poder; y como enfatiza Freire (1992), el escenario ético que supone la educación ha de sostenerse en una relación de respecto educador-educando que posibilite una construcción de lo que es propio. En el segundo, en la visión modernista, quedaría excluido del proceso de racionalidad comunicativa cualquier forma de subjetividad, por lo que no podemos asumir los planteamientos defendidos en párrafos anteriores. Esta idea puede apreciarse de forma clara en la siguiente figura, extraída de Booth y Ainscow (2016). En la misma línea, los autores establecen un marco de valores excluyentes que aportan significado a la comprensión de lo que representan los valores inclusivos — por la naturaleza dicotómica de estos en sí-, y lo hacen contextualizados en su experiencia.

Figura 1.

Marco de valores incluyentes y excluyentes
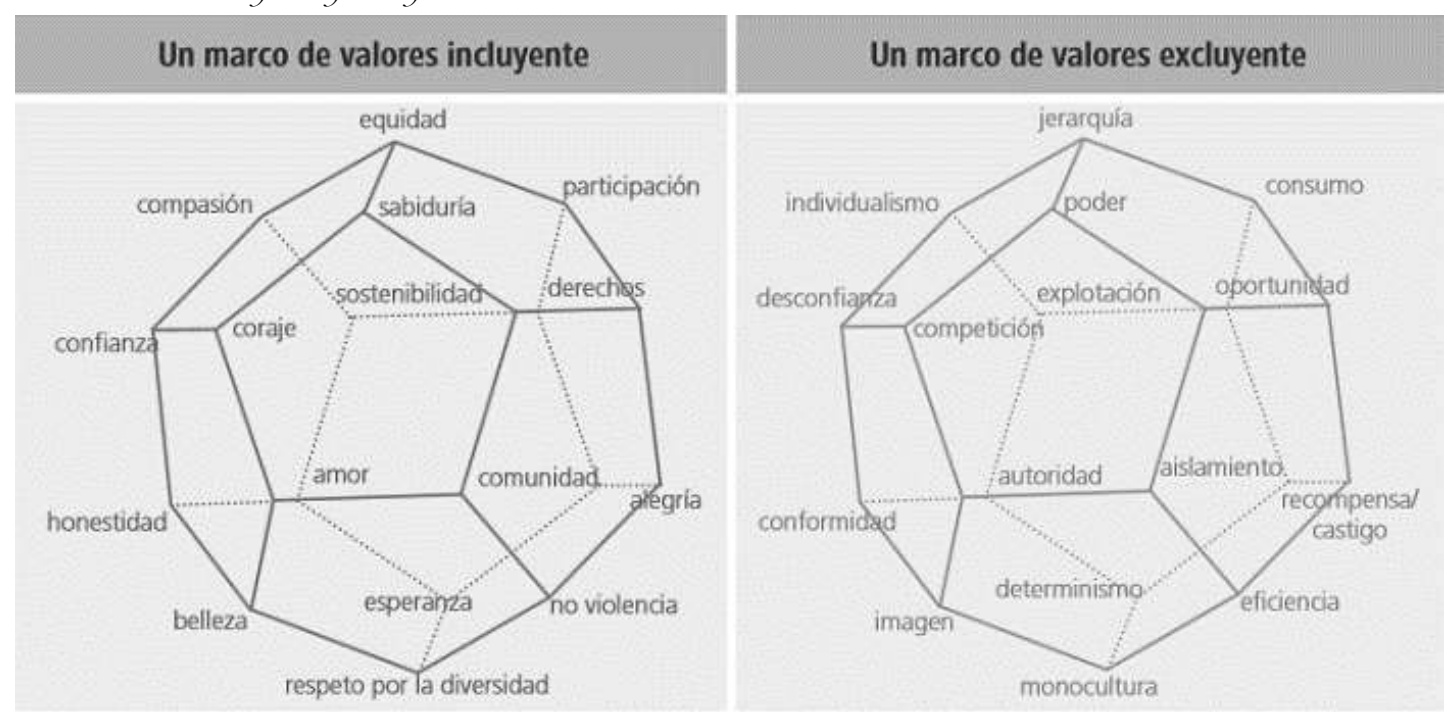

Fuente: Booth y Ainscow (2016, p. 32). 
Si observamos la Figura 1, se aprecia cómo el poliedro de valores incluyentes incorpora uno que no se encontraba en las tablas anteriores, la sabiduría, contrapuesto al poder dentro de los valores excluyentes; lo que supone una clara referencia a la esencia del razonamiento comunicativo habermasiano. Este poliedro también resulta de interés para dilucidar, a pesar de que el propio texto del Index lo hace, el significado profundo de cada valor expuesto, y superar las críticas al propio Índice de Inclusión. Booth y Ainscow (2016) apuntan que son frecuentes dichas críticas a esta selección de valores y a las cuestiones en relación a la elección de por qué estos y no otros. Señalan que, a menudo, esto tiene que ver con una cuestión lingüística y de traducción, más que con lo que entraña cada uno de ellos.

En la Tabla 2, comparativa entre las versiones de valores, vemos que la libertad ha desaparecido, argumentando que esta se da en la interacción entre derechos y participación; justificación que asumiríamos en cuanto que no supone una eliminación sino una construcción desde valores presentes. Sin embargo, aceptando que este es un marco interactivo, nosotros necesitamos la libertad como valor, en cuanto que esta es el fundamento desde el que se construye la igualdad (Sen, 2010). También ha desaparecido como valor la ciudanía democrática, cuya esencia pivota en la igualdad, la participación, la comunidad, etc.; asunto con el que mostramos nuestro acuerdo para evitar confundir este valor con el de ciudadanía democrática formal que adolece del carácter participativo.

Observamos también cómo, frente a la versión del 2002, ya no se habla de tolerancia, puesto que esta supone una actitud de condescendencia con el otro o la otra; si bien la tolerancia también puede entenderse, como señalan Parrilla y Daniels (1998), como una actitud favorable del profesorado hacia las personas «más difíciles de enseñan» y hacia las situaciones complejas en la enseñanza. Aquí preferimos aludir al respeto como elemento más definitorio de dicha actitud. En el caso de la equidad, es sustituida por la igualdad. La igualdad en este marco de valores implica ser tratado con igual valor, no en los mismos términos. Aun así, en este caso, por las connotaciones sociales y lingüísticas en nuestro contexto, preferimos utilizar como valor la equidad porque supone una interacción entre la igualdad, la libertad y la justicia.

Asimismo, nos parece especialmente significativa la inclusión de dos valores en esta relación, en concreto esperanza/optimismo y coraje, en cuanto que presentan la esencia de la búsqueda de una transformación necesaria, que precisa de ello para afrontar lo que estamos planteando, y que supone una lucha contra-hegemónica.

\section{Las éticas de la educación inclusiva}

Señalábamos con anterioridad que la ética de la educación inclusiva se orienta desde valores y principios. Hasta el momento hemos pensado en relación con el papel que estos juegan y hemos identificado y declarado los valores desde los que se construye nuestra concepción de educación inclusiva. Partiendo de que la ética a la que nos referimos «se sabe afrontada por la manifestación discriminatoria de raza, género, clase» y que «no importa si trabajamos con niños, jóvenes o adultos, por la que debemos luchar» (Freire, 1997, pp. 17-18), necesitamos dar un paso más allá en la identificación de las concepciones éticas desde las que se sostienen dichos valores. Toca, pues, poner nombre a las éticas de la educación inclusiva.

Para ello señalamos que, si bien numerosos trabajos aluden a la importancia de la ética como sustento de la misma, no ocurre lo mismo en relación con las fuentes, como tradiciones éticas, en la que encuentran soporte en el marco de la literatura científica en torno a la educación inclusiva. Entre los existentes y que nos resultan de interés para situar nuestra posición, podemos destacar los trabajos de Maturana $(1992,1994,1999)$ y López Melero (2005) desde una orientación centrada en la convivencia, de Etxeberría (2000) y Skliar (2008) desde las diferencias, o Escudero (2006, 2016), Escudero y Martínez (2011) y Echeita, Simón, López y Urbina (2013) en una orientación hacia la mejora de la escuela desde una perspectiva democrática. Esta identificación basada en referentes de la educación inclusiva es la que nos lleva a nombrar las éticas desde las que se sostienen nuestros valores en acción, configurando un entramado que partiendo de la aportación de Escudero (2016) se amplía y resignifica desde la percepción comunitaria de la inclusión (Parrilla, Susinos, Gallego y Martínez, 2017). Se concretan, pues, en la ética de la diferencia, la ética de la convivencia, la ética de la justicia, la ética del cuidado, la ética de la crítica, la ética de la profesionalidad y la ética comunitaria. La tabla que mostramos a continuación ilustra 
la relación entre los valores declarados de la educación inclusiva y su sostén desde las diferentes éticas nombradas.

Tabla 3.

Relación entre valores declarados y éticas de la Educación Inclusiva

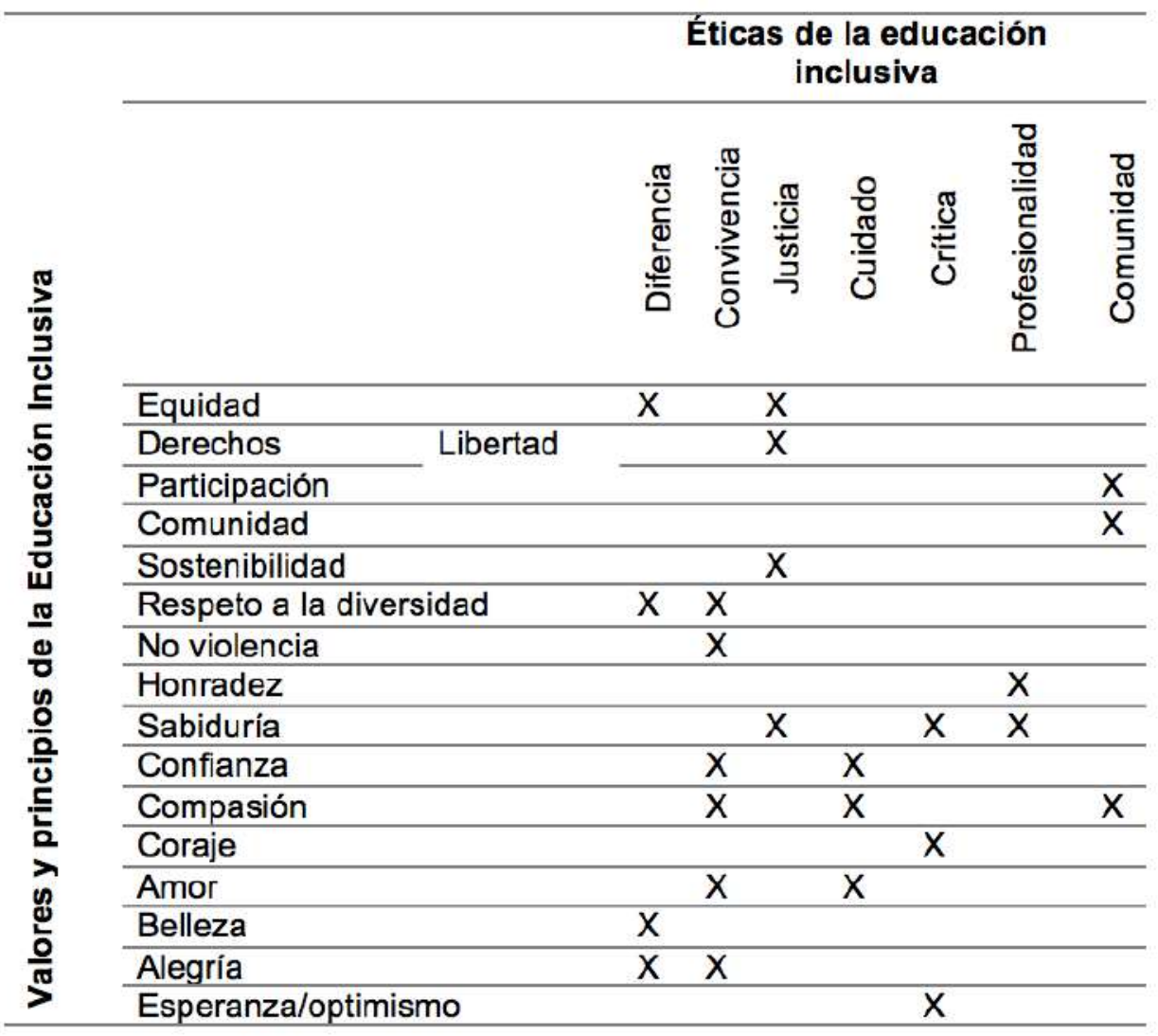

Fuente: elaboración propia.

La ética de la diferencia. Permite un posicionamiento en relación con la naturalización de estas en la esencia del ser humano; y una reconstrucción de la visión de las mismas de una manera positiva, como una fuente de enriquecimiento colectivo. En este sentido, Skliar (2008) resalta lo importante que es enfatizar, a través de nuestro lenguaje, la distinción entre esas diferencias y la construcción categórica del diferente por oposición a la norma - aportación que toma como fuente el pensamiento de Lévinas (1977). Asimismo, reivindica la diferencia como norma, de modo que «lo anormal» será la configuración de esa contra-naturaleza.

Desde esta perspectiva, la diferencia no necesita ser incluida puesto que se configura en nuestra esencia, de modo que la situación problemática se origina en otro lugar: el de pensar en el encuentro con el otro o la otra. La ética de la diferencia también posibilita tomar conciencia de que la desigualdad emerge de la cultura y que, por tanto, es construida socialmente a partir de los rasgos y elementos que se comparten, y desde los que crecemos (Etxeberría, 2000); lo que está en la base de la argumentación freireana. El aporte de la ética de la diferencia a la perspectiva de la educación inclusiva tiene que ver con la posibilidad de someter a revisión y análisis las categorizaciones culturales que se hacen de las propias diferencias, a fin de abordar el dilema dicotómico nosotros-los otros y las lecturas norte-sur de esas categorías (De Sousa Santos, 2009), además de los marcos universales que se sitúan en oposición a las esencias particulares. Este es un asunto sobre el que Freire nos interpela a través de su obra, situando incluso la cuestión en primera persona. Recordemos, a modo de ejemplo, su propio tránsito concientizador en torno al lenguaje inclusivo: 
Siempre digo hombres y mujeres porque aprendí hace ya muchos años, trabajando con mujeres, que decir solo hombres es inmoral (...). Aprendí que en gramática el masculino prevalece (...) esto que parece una cuestión de gramática es una cuestión de ideología (Freire, 2003, p. 32).

La ética de la convivencia. Nos habla de ese encuentro con el otro, la otra en la que se centra la educación inclusiva y que, en el pensamiento de Freire, se sitúa en la esencia de su ética universal del ser humano. En palabras del autor: «Cuando hablo de la ética universal del ser humano estoy hablando de la ética en cuanto marca de la naturaleza humana, en cuanto a algo absolutamente indispensable a la convivencia humana» (Freire, 1997, p. 15). En este significar, esta ética de la convivencia la interpretamos como un encuentro que parte de sí para brindar la relación con los otros y otras y que ofrece la oportunidad de compartir. Un conocimiento mutuo posibilitado por el establecimiento de relaciones basadas en el valor de la comprensión y la aceptación; valores que son precisamente fruto del reconocimiento de las diferencias (López Melero, 2005). Sin olvidar cómo todo ello tiene su base en la esencia amorosa del ser humano (Maturana, 1999) y que se favorece gracias a ese reconocimiento de la subjetividad dado en la relación de respeto y que permite acercar los sentidos y lo emocional en los procesos de naturaleza más racionales (como la teorización y explicación de las diferencias).

La ética de la justicia. Se sitúa desde una posición que trata de legitimar los valores desde el derecho; como en el caso del derecho a la educación y a su articulación, el dilema de la igualdad o el de la equidad, como conceptos clave adheridos en la educación inclusiva (Escudero, 2006). Nos gustaría aclarar que, dentro de esa idea de igualdad de derechos, existe una creencia que persiste al considerar que hay un mismo rasero con el que medirnos para alcanzar ser iguales — ante la ley. Por ello, siguiendo las ideas planteadas por Sen (1995) y Contreras (2002), consideramos que bajo esa necesidad de igualdad (ipara todos lo mismo por derecho!) se desvela una idea de «desigualdad», al querer ofrecer lo mismo a quien precisa, en esencia, algo distinto.

Lo que nos lleva a hablar de la necesidad de justicia distributiva y de equidad que emerge de ella (Rawls, 2002). Pero, además, asumimos un enfoque de las capacidades que, partiendo de la importancia de la citada redistribución para la conquista de la equidad, precisa de la conversión de los recursos en libertades (Bolivar, 2006). Esto supone que la educación ha de estar al servicio de romper la lógica de la desigualdad, generando la libertad suficiente que permita al propio individuo salir de esa lógica, que es lo que conocemos en la educación inclusiva como empoderamiento.

Además, la ética de la justicia nos lleva a asumir que en la esencia de la educación inclusiva podemos identificar, al menos, las justicias que precisa la escuela pública hoy: una justicia cognitiva, afectiva y ecológica (Angulo, 2016). Todas ellas entendidas como derechos de los niños y niñas en distintas direcciones: a acceder a un conocimiento valioso que les permita tanto desenvolverse en el mundo en el que vivimos, como transformarlo; a ser cuidados, amados y protegidos (a lo que nosotros añadimos la visión de reciprocidad); y a vivir una recuperación de la esencia del ser humano en armonía con el otro o la otra y con la naturaleza (lo que se encuentra en la esencia de lo que entendemos por sostenibilidad).

La ética del cuidado. Alude a una justicia afectiva que invita a pensar la responsabilidad que tenemos en relación con el otro o la otra, que se descubre en la compresión del mundo como una red de relaciones y en equilibrio entre el cuidado de los demás y el cuidado propio - que ha de trascender la esfera de lo privado para ser reconocida en el espacio público- (Gilligan, 1982). El pensamiento de la educación inclusiva, desde la perspectiva relacional del cuidado, resulta de sumo interés porque propone a las personas construirnos como redes de apoyo; esto está en la base de la cooperación, de la colaboración interprofesional y los grupos de apoyo mutuo o de las redes comunitarias, donde la ayuda emerge como una práctica representativa y valorada. Idea que se encuentra en la base del diálogo, la escucha e incluso el silencio que, para Freire (1997), son inherentes a esta ética del cuidado que abordamos.

Para Escudero (2006) el cuidado nos conduce a una visión cívica en el contexto de la educación inclusiva; esta visión cívica implica poner a los otros y las otras en el centro de las decisiones propias y de nuestra práctica lo que, para nosotras, en una versión recíproca nos resitúa, pues de lo contrario supondría un plegamiento al puro servicio. La versión recíproca viene dada por la estructura en red.

Esta ética de cuidado y la de la justicia se han visto en ocasiones confrontadas por la base emocional de la primera frente a la racional de la segunda. Sin embargo, hoy en día se habla de una nueva re- 
conceptualización donde existe una reconciliación entre ambas. Esta viene dada por la subjetivación de la justicia, que implica que:

La justicia está conectada con el cuidado, la solidaridad, la compasión y la empatía. Y el cuidado nos ayuda a reconocer las obligaciones de justicia que tenemos con otros (independientemente de si se encuentran cerca o lejos de nosotros). El cuidado como práctica democrática ofrece un programa político que puede equilibrar los derechos y las responsabilidades. (Comins, 2015, pp. 173-174).

En el mismo sentido apunta Bennhabib (1992), quien la halla a través de la ética discursiva de Habermas y los principios de discurso práctico una vía de reconciliación. En esta resulta imprescindible concebir como necesarias las cuestiones personales como cuestiones morales, a la par que declara no perder de vista el universalismo ofrecido por la justicia, que garantiza el mismo valor para cada ser humano.

La ética crítica. Aporta a la educación inclusiva la cualidad de conformarse en una práctica de libertad (Freire, 1976). Y esta supone la mirada atenta hacia los procesos y los contextos para denunciar la injusticia y la exclusión, en un acto que aborda la realidad y la somete a cuestionamiento a través de los valores y principios propios de la educación inclusiva. Ello supone algo más que el descubrimiento de las barreras que obstaculizan el desarrollo de la inclusión, también invita a desentrañar los cómo y los por qué. Para Escudero (2006), la ética crítica supone «(...) la denuncia y el cuestionamiento de situaciones educativas injustas, despersonalizadas, atentatorias contra la dignidad de los estudiantes o de otros protagonistas educativos, irresponsables, frías o carentes del sentido de acogida y solidaridad» (p. 30).

Entendemos que entre las aportaciones fundamentales a esta ética se encuentran las de Freire (1997) para quien esta supone un proceso personal que se asienta en lo colectivo. Entre sus numerosas aportaciones hemos de destacar el proceso de concientización, a través del cual pensamos dichas barreras y obstáculos: en primer lugar de manera mágica, que supone una mirada impotente ante situaciones que se identifican como no cambiantes; en segundo, de manera ingenua, reconociendo la situación problemática y la relación entre opresión y opresor; por último, un momento crítico, donde se entienden los mecanismos que operan en dicha relación para su superación, lo que se construye desde el diálogo en lo colectivo. También tomamos la visión situada de la ética, algo imprescindible en una concepción de la educación inclusiva como proceso. Desde aquí los valores tienen sentido en relación con la cultura de un contexto y una época histórica determinada.

La ética de la profesionalidad. Como ya sabemos, Freire alude en su obra de forma continua a la relación entre ética y educación, y de igual modo supone una constante alusión a la esencia ética de la profesión docente en el contexto de prácticas concientizadoras. La ética de la profesionalidad se refiere a «las capacidades y las responsabilidades que han de poseer los profesionales al desempeñar su trabajo, sobre todo aquellos que lo hacen en instituciones que velan por los intereses comunes» (Escudero, 2006, p. 31). Todo ello, trasladado a la educación inclusiva, supone el reconocimiento de la necesidad de incluir en los currículos de formación de profesionales de la educación el tratamiento de la ética y, particularmente, del cuestionamiento y la toma de conciencia a través de procesos problematizadores de los valores a los que nos hemos referido en apartado anteriores. Así, Escudero, González y Fernández (2013) nos hablan de la importancia de la presencia en esta de contenidos (como ideas y prácticas) que aborden las diferencias, la justicia, el cuidado y la equidad que posibiliten la revisión crítica de los procesos y los contextos donde se articula la profesión docente, siendo esta una herramienta al servicio de la transformación.

La ética de la profesionalidad no solo se refiere a la formación inicial del profesorado, lo hace también hacia el propio ejercicio de los valores de la educación inclusiva en nuestras prácticas docentes e investigadoras. Ello implica el análisis de nuestras propias actuaciones y en ellas del diseño, desarrollo y evaluación de las mismas, asumiendo esos principios de la inclusión. Es decir, nos habla de una práctica profesional de la educación inclusiva desde la inclusión entendida por López Melero (2000), Parrilla (2010) o Nind (2014).

La ética comunitaria. Expresa nuestra responsabilidad de involucrarnos en los procesos comunes (Furman, 2004). En la educación inclusiva, ello nos vincula a nuestro entorno, a lo local, desde un lugar desde el que construir alternativas. Necesitamos partir de los cambios en nuestro entorno próximo para extender redes que permitan articular propuestas más amplias y complejas. Esto es porque el trabajo en nuestra comunidad nos permite adentrarnos en sus claves, compartirlas y construirlas, 
lo que se encuentra en la esencia de la alfabetización freireana que, trasladada al presente, encuentra su sentido en cómo los procesos educativos permiten al sujeto por sí mismo y en comunidad interpretar el mundo.

Una de las claves de la ética comunitaria es la participación, ya que desde ahí se reconoce al otro como igual en valor, se construyen relaciones de reconocimiento que crean entornos seguros y de confianza y que nos permiten, de un lado, aprovechar el potencial de saberes de la comunidad y, de otro, enfrentarnos acompañados a las experiencias de cambio. A través de esta ética comunitaria, tan presente en textos de Freire (1994) como Cartas a quien pretende enseñar - y tan asociada a la ética de la solidaridad humana (Freire, 1997)—, nos ponemos al servicio de las necesidades auténticas de la comunidad que encuentran un espacio para ser escuchadas, reconocidas, dialogadas y abordadas de manera conjunta.

\section{El acontecimiento ético de la educación}

Para finalizar este texto, parafraseamos el título del libro La educación como acontecimiento ético de Fernando Bárcena y Joan Carles Melich (2014) para rescatar una idea que nos parece clave: cómo pensar éticamente la educación es una forma de aceptar lo imprevisible que se da en el propio acto educativo; y cómo la ética concede a la educación la cualidad de «acontecimiento» al permitir abrir la mirada a las diferencias como una oportunidad de creación conjunta. A continuación, recogemos algunos «focos de atención», a modo de hilos, en los que nos interesa detenernos para continuar pensando la educación inclusiva desde su apuesta por la ética. Comenzaremos estos hilos abriendo la cuestión de la responsabilidad personal por las relaciones con los otros y las otras, para acercarnos a la naturaleza de la ética desde su esencia amorosa y finalizar con una esperanza: mirar el mundo desde todas sus posibilidades.

(i) Convivir es aceptar al otro desde quien es. Hablar de convivencia, como hemos ido apuntando, nos traslada al plano social y compartido desde una implicación de respeto y aceptación de las diferencias. Ya que, como sostiene Freire (1976), el yo se configura a través de un no-yo. Eso significa que, para ser sujetos autónomos y libres, nos necesitamos; necesitamos de la relación con las otras y los otros, y lo que ello comporta. Pero esto supone a su vez la aceptación del otro o la otra desde su propia subjetividad (él es un otro para mí; pero yo soy también otro para el otro) y no desde la imposición de nuestra mirada (Sierra y Caparrós, 2017). Esta máxima requiere de un alto compromiso por parte de cada sujeto (personal) para aceptar las singularidades como parte del ser humanos. A veces, nos encontramos con posturas paternalistas que miran al otro o la otra con condescendencia, cosificando lo que nos es ajeno para atenderlo, desnaturalizándolo. En esos casos, no estaríamos hablando de una convivencia ética, pues la diferencia, su significado y su valoración pasarían por lo que en líneas anteriores hemos considerado el desarrollo de una ética heterónoma (una norma extendida y aceptada que mide qué es válido y qué no lo es).

(ii) Aprender a mirar el yo que mira. A lo largo del texto hemos ido haciendo referencia a la importante idea de reconocimiento del otro o la otra desde quien es. Esto hace confluir la noción de ética con la de educación inclusiva en la siguiente idea: aceptar las diferencias requiere revisar desde dónde miramos y escuchamos a los otros; y también necesita reflexionar desde donde los concebimos y los valoramos, a fin de conseguir crear lazos que nos unan. Se trata de una posición personal de aprender a mirar al yo que mira, que nada tiene que ver con posturas solipsistas. Esta idea está íntimamente relacionada con lo que Burguet y Buxarrais (2014) proponen como desarrollo de la interioridad, entendido como un espacio de apertura que pasa por la reconciliación con el propio ser a fin de abrirse a la relación, con conciencia y respeto. Si lo situamos en el plano de la educación inclusiva, podemos afirmar que cualquier acto educativo se debe a su esencia y naturaleza relacional; de modo que ser y estar con los otros y las otras siempre necesita ser conducido desde sí.

(iii) No bay razón práctica sin sentimiento. Esta afirmación que tomamos de Camps (2010) nos lleva a plantearnos el sentido de la ética tradicional —encargada fundamentalmente de clasificar dicotómicamente las acciones como «buenas» o «malas», «correctas» o »incorrectas» — a fin de superarla. La autora tiene la intención de introducir la noción de sensibilidad en la construcción del mundo de valores, lo que refleja que la esencia de la ética no está solo en discernir lo bueno o lo malo (ética material); pues eso corresponde con una construcción social contextual que es legitimada para crear normas. A nuestro modo de ver, la incorporación de la noción de sensibilidad como valor ético aporta a nuestra mirada inclusiva un lugar que reconoce el mundo emocional del propio sujeto y las implicaciones que 
para cada quien tienen los valores y las normas, como obligaciones sociales que a priori son una construcción externa. Según Camps, lo que precisamos es una interiorización de esos valores en la convivencia porque suponen el proceso más íntimo y una transformación personal no impuesta. Otros autores, como Maturana $(1992,1994)$ o Salomon $(2007)$ también hacen referencia a que el origen de la ética está en la emoción y no exclusivamente en la razón; esto supone un giro copernicano, pues pone «patas arriba» la creencia de buena parte de la tradición que sitúa a la ética desde posiciones más conductistas o cognitivas.

(iv) Más allá de la norma y la razón, la emoción. Maturana (1999) considera que la ética no puede ser en primera instancia normativa, porque ello supondría la negación del otro o la otra. A nuestro modo de ver, la norma es per se un constructo teórico y racional (externo), aun cuando esta es acordada y legitimada bajo diálogo y en consenso. De este modo, la norma se mueve en terrenos de lo válido y lo no válido, y no de lo posible (como sugiere la ética freireana). La naturaleza impositiva de la norma niega toda posibilidad e imprevisibilidad, cualidades que son justamente propias de las relaciones en convivencia y, por ende, de la educación inclusiva. La negación de lo ajeno, de lo diferente, no hace más que invisibilizar todas las «posibilidades posibles» que tienen las personas de ser y estar en el mundo. Por eso, la educación inclusiva apuesta por el compromiso y el desarrollo de escenarios de convivencia que permitan la interiorización personal y voluntaria de los valores y las acciones, permitiendo así reconciliar la razón y la norma con la emoción (Camps, 2010).

(v) La esperanza como utopía aporta a la educación inclusiva su capacidad de mirar más allá de las normas sociales y las obligaciones morales. Permite un escenario que visualiza un mundo mejor y más justo para todas y todos. Sobre la utopía habla Parrilla (2002) aludiendo a cómo el «pensamiento utópico» es un ejercicio de provocación crítica y estimulante que posibilita a la educación inclusiva servir de incentivo para repensar las prácticas escolares desde todas sus dimensiones (estructural y organizativa, didáctica, pedagógica y política). Y es que, como sostiene la autora, «Una utopía, [...], es un nuevo modo de pensar sobre algo. Las utopías nos permiten ver con nuevos ojos aquello que, por común y habitual, parece incuestionable» (p. 7).

La esperanza es acción, requiere movimiento. Como bien nos recuerda Freire (1992), la ética de la esperanza no se desarrolla desde un estado inmovilista. Es el convencimiento de que las cosas, la vida, la educación pueden ser de otro modo; por eso consideramos que la educación inclusiva, desde ese pensamiento ético que transforma lo inevitable en esperanza, es una forma de convivencia respetuosamente transgresora, que rompe las fronteras (de la razón).

\section{Referencias}

Allan, J. (2005). Inclusion as an Ethical Project. In S. Tremain (2005) Foucault and the Government of Disability, (pp. 281-297). Ann Arbor: The University of Michigan Press. doi: 10.3998/mpub.8265343.

Angulo, J. (2016). Las justicias de la Escuela Pública. Revista Interuniversitaria de Formación del Profesorado, 30(1), pp. 37-47.

Bárcena, F. \& Melich, J. C. (2014). La educación como acontecimiento ético. Natalidad, narración y hospitalidad. Madrid: Miño y Dávila. Disponible en: http://ve.scielo.org/scielo.php?script=sci_arttext\&pid=S1010-

$29142010000200013 \& \operatorname{lng}=$ es\&nrm $=$ iso.

Bennhabib, S. (1992). Una revisión del debate sobre las mujeres y la teoría moral. Isegoría, 6, pp. $37-$ 63. doi: https://doi.org/10.3989/isegoria.1992.i6.323

Booth, T. (2002). Inclusion and Exclusion in the city: concepts and contexts. In P. Potts \& T. Booth (Eds). Inclusion in the city (pp. 1-14). Londres: Routledge. doi: https://doi.org/10.4324/9781315014494

Booth, T. (2006). Manteniendo el futuro con vida; convirtiendo los valores de inclusión en acciones. In M. Á. Verdugo Alonso \& B. Jordán de Urríes. (Coords.). Rompiendo inercias. Claves para avanzar. VI Jornadas científicas de Investigación sobre personas con discapacidad (pp. 211-218). Salamanca: Amarú.

Booth, T. \& Ainscow, M. (2002). Índice de inclusión. Desarrollando el aprendizaje y la participación en las escuelas. Bristol: CSIE.

Booth, T. \& Ainscow, M. (2016). Índice de inclusión. Desarrollando el aprendizaje y la participación en las escuelas $-6^{a}$ versión. Bristol: CSIE. 
Camps, V. (1986). Ética de la Esperanza. Estudios. filosofía-historia-letras. doi: https://doi.org/10.5347/01856383.0004.000169677

Camps, V. (2010). El Gobierno de las emociones. Barcelona: Heder.

Caparrós, E. (2015). La formación y la pedagogía desde el «sen». Pensar-nos en relación a la infancia y la juventud en riesgo. In Hormaeneche, L. D. \& Sierra, J. E. (Comps.). Problemáticas contemporáneas en torno a la educación de los jóvenes, pp. 18-31. San Salvador de Jujuy: Purmamarka.

Caparrós, E.; Bordini, F. \& Rodríguez, D. (2020). La experiencia de investigar en el IES Cartima (Málaga) como oportunidad para repensar la inclusión y la innovación educativa. In Caparrós, E., Gallardo, M., Alcaraz, N. \& Rizzo, A. L. (coords.). Educación inclusiva. Un desafio y una oportunidad para la innovación educativa en la formación inicial del profesorado (pp. 101-114). Barcelona: Octaedro.

Carrillo, I. (2005). Diez valores para el siglo XXI. Madrid: Ciss Praxis.

Contreras, J. (2002). Educar la mirada... y el oído. Percibir la singularidad y también las posibilidades. Cuadernos de pedagogía, 311, pp. 61-65.

Corbett, J. (1996). Bad - Mouting. The language of Special Needs. London: Falmer.

Corbett, J., \& Slee, R. (2000). An international conversation on inclusive education. In F. Armstrong, D. Armstrong \& L. Barton (Eds.), Inclusive education: Policy, contexts and comparative perspectives (pp. 133-146). London, England: David Fulton.

Comins, I. (2015). La ética del cuidado en sociedades globalizadas: hacia una ciudadanía cosmopolita. Thémata. Revista de Filosofia, 52, pp. 159-178. doi: https://doi.org/10.12795/themata.2015.152.09

De Sousa Santos, B. (2009). Una epistemología del Sur: la reinvención del conocimiento y la emancipación social. Buenos Aires: Siglo XXI.

Echeita, G., Simón, C., López, M., \& Urbina, C. (2013). Educación inclusiva. Sistemas de referencia, coordenadas y vórtices de un proceso dilemático. In M. A. Verdugo y R. L. Schalock (Eds.), Discapacidad e inclusión. Manual para la docencia. (pp. 307-328). Salamanca: Amarú.

Escudero, J. M. (2006). Compartir propósitos y responsabilidades para una mejora democrática de la educación. Revista de Educación, 339, pp. 19-42. Disponible en: http://www.educacionyfp.gob.es/revista-de-educacion/numeros-revista-educacion/numeros-anteriores/2006/re339/re339-02.html.

Escudero, J. M. (2016). Éticas de la profesión docente y lucha contra el fracaso escolar. In J. M. Escudero (Coord.) Inclusión y exclusión educativa: realidades, miradas y propuestas (pp. 189-201). Valencia: Nau Llibres.

Escudero, J. M., González, M. T., \& Rodríguez, M. J. (2018). Los contenidos de la formación continuada del profesorado: ¿Qué docentes se están formando? Educación XX1, 21(1), pp. 157-180, doi: https://doi.org/10.5944/educxx1.20183

Escudero, J. M., \& Martínez, B. (2011). Educación inclusiva y cambio escolar. Revista Iberoamericana de Educación, 55, pp. 85-105. doi: https://doi.org/10.35362/rie550526

Etxeberría, X. (2000). Ética de la diferencia (Vol. 5). Bilbao: Universidad de Deusto.

Freire, P. (1970). Pedagogía del oprimido. Madrid: S. XXI.

Freire, P. (1974). Concientización. Teoría y Práctica de la Liberación. Ediciones Búsqueda. Argentina.

Freire, P. (1976). La educación como práctica de la libertad. México: Siglo XXI Editores.

Freire, P. (1990). La Naturaleza política de la educación. Cultura, poder y liberación. España: Ediciones Paidós.

Freire, P. (1992). Pedagogía de la esperanza: un reencuentro con la pedagogía del oprimido. México: Siglo XXI Editores.

Freire, P. (1994). Cartas a quien pretende enseñar. México: Siglo XXI Editores.

Freire, P. (1997). Pedagogía de la autonomía. Saberes necesarios para la práctica educativa. México: Siglo XXI Editores.

Freire, P. (2003). El grito manso. Argentina. Siglo XXI Editores.

Furman, G. (2004). The ethic of community. Journal of educational administration, 42(2), pp. 215-23. doi: $10.1108 / 09578230410525612$.

Greenstein, A. (2015). Radical inclusive education: Disability, teaching and struggles for liberation. London: Routledge. doi: 10.4324/9781315690483.

Gilligan, C. (1982). In a Different Voice: Psychological Theory and Women's Development. Cambridge: Harvard University Press. doi: https://doi.org/10.1108/09578230410525612

Habermas, J. (1987). Teoría de la acción comunicativa. Tomos I y II. Madrid: Taurus. 
Jover, G. \& Gil Cantero, F. (2003). La contribución de la educación ética y política en la formación del ciudadano. Revista de Educación, no extra de 2003 (ejemplar dedicado a: Ciudadanía y Educación), pp. 109-129. Disponible en: http://www.educacionyfp.gob.es/dam/jcr:d8cb5a6f-f494-498caa21-4f92ab4fd422/re20030611399-pdf.pdf.

Larrosa, J. \& Skliar, C. (2001). Los habitantes de Babel: Politicas y poéticas de la diferencia. Barcelona: Laertes. Lévinas, E. (1977). Totalidad e Infinito. Salamanca: Sígueme.

López Melero, M. (2000). Ideología, diversidad y cultura: construyendo una escuela contrahegemónica. In J. I. Rivas (Coord.). Profesorado y reforma: ¿ un cambio en las prácticas de los docentes (pp. 81-100). Málaga: Aljibe.

López Melero, M. (2004). La ética y la cultura de la diversidad en la escuela inclusiva. Tavira: Revista de Ciencias de la Educación, 20, pp. 9-26.

López Melero, M. (2005). Educación, amor, ética... caminos para construir un sueño: la escuela inclusiva. Tavira: Revista de Ciencias de la Educación, 21, pp. 11-28.

Maturana, H. (1992). Emoción y lenguaje en educación y política. Santiago de Chile: Pedagógicas Chilenas.

Maturana, H. (1994). El sentido de lo humano. Santiago de Chile: Dolmen.

Maturana, H. (1999). Transformación en la convivencia. Santiago de Chile: Dolmen.

Nind, M. (2014). What is Inclusive Research? London: Bloomsbury Academic. doi: $10.5040 / 9781350192324$.

Parrilla, Á. (2002). Acerca del origen y sentido de la educación inclusiva. Revista de Educación, 327, pp. 11-29.

Parrilla, Á. \& Daniels, H. (1998). Creación y Desarrollo de Grupos de Apoyo entre Profesores. Bilbao: Mensajero.

Parrilla, Á., Susinos, T., Gallego, C. \& Martínez, B. (2017). Revisando críticamente cómo investigamos en educación inclusiva: cuatro proyectos con un enfoque educativo y social. Revista Interuniversitaria de Formación del Profesorado, 89, pp. 145-156. Disponible en: https://www.redalyc.org/articulo.oa?id=27452662011.

Rawls, J. (2002). Justicia como equidad. Una reformulación (traducción de Andrés de Francisco). Barcelona: Editorial Paidós.

Scheler, M. (1973). Formalism in Ethics and Non-Formal Ethics of Values. A New Attempt toward the Foundation of an Ethical Personalism. Evanston, IL: Northwestern University Press.

Sen, A. (2010). La idea de la justicia. Madrid: Taurus.

Sierra, J. E. \& Caparrós, E. (2017). Apuntes acerca de la formación de educadoras y educadores y el desarrollo de la interioridad. In Martin, V. \& Castilla, T. (Coords.). Aproximaciones a las complejidades de la par, pp. 69-76. GEU: Granada.

Skliar, C. (2008). ¿Incluir las diferencias? Sobre un problema mal planteado y una realidad insoportable. Orientación y sociedad, 8. Disponible en: http://www.scielo.org.ar/scielo.php?pid=S1851$88932008000100002 \&$ script $=$ sci_arttext\&tlng $=$ en.

Slee, R. (1995). Changing theories and practices of discipline. London: The Falmer Press.

Slee, R. (2012). La escuela extraordinaria: exclusión, escolarización y educación inclusiva. Madrid: Morata.

Solomon, R. (2007). Ética emocional: una teoría de los sentimientos. Madrid. Paidós Ibérica.

Stainback, S. \& Stainback, W. (1999). Aulas inclusivas: Un nuevo modo de enfocar y vivir el curriculo. Madrid: Narcea. 